\title{
Isozyme markers for self-compatibility and yield in Theobroma cacao (cacao)
}

\author{
JOHN WARREN*, SUNITA MISIR \& KALAI† \\ Cocoa Research Unit, University of the West Indies, St. Augustine, Trinidad and Tobago and $P$ PNG Cocoa and Coconut \\ Research Institute, Rabaul, Papua New Guinea
}

\begin{abstract}
Self-incompatible cacao clones were observed to out-yield self-compatible clones in a 20-year trial. In another trial, self-compatible trees were seen to set three times more pods than did the selfincompatible trees. However, because of the abortion of young pods this difference had disappeared by the time the pods reached maturity. Isozyme analysis revealed that both the $A c p$ and Idh loci were linked to one of the loci controlling compatibility type. Thus, isozyme screening of seedlings could be used to predict the compatibility type and hence pod-set and, possibly, yield of the mature tree.
\end{abstract}

Keywords: cacao, compatibility type, isozyme markers, Theobroma cacao, yield.

\section{Introduction}

The cacao tree, Theobroma cacao, which is a major cash crop in the west of Africa and Brazil, has received little in the way of serious plant breeding (Warren \& Kennedy, 1991) and few qualitative agronomic traits are known in cacao (Warren, 1992). Although genetic markers are available (Wilde et al., 1992), none has been demonstrated to be linked in inheritance to agronomic traits. Knowledge of the linkage relationships between isozyme loci and qualitative trait loci would be especially useful to breeders of tree crops where field trials are long-term and expensive.

The three unlinked loci controlling compatibility in cacao have been known for 30 years (Knight \& Rodgers, 1955; Cope, 1962). Self-compatibility is recessive at all three of these loci, which are designated $A, B$ and $S$. Genotypes homozygous recessive at one or more of these loci are self-compatible. Although the majority of cultivated cacao trees are self-compatible, the influence of the trait upon yield remains unclear. No easy way of screening for self-compatibility exists other than growing the tree to maturity and manually selfing bagged flowers.

The objective of this study was to establish the influence of compatibility type upon yield in cacao and then to seek isozyme markers linked to the trait.

*Present address and correspondence: Department of Land Resources, Scottish Agriculture College, 581 King Street, Aberdeen AB9 1UD, U.K.

\section{Materials and methods}

\section{Clonal field trial}

In 1939, the late Professor Cheesman established a field trial of 100 Imperial College Selection (ICS) cacao clones at San Juan Estate in Central Trinidad. These ICS clones, which included both self-compatible and self-incompatible types, had previously been selected from estates around Trinidad for their high yield (Pound, 1935). One individual of each of the 100 clones was raised in each of five completely randomized blocks. The annual mean dry weight of beans produced over the five replicates was recorded over a 20 -year period from the second year after planting. Although the data were compiled over 30 years ago they have never been analysed in respect of compatibility type. For each of 31 self-compatible and 47 selfincompatible clones the total yield over the entire 20 -year period was calculated and then averaged over the five replicates per clone. The compatibility type of the remaining 22 clones is not known, so they were not included in the analysis. A one-way analysis of variance was then performed on the mean total yield of the 31 self-compatible and the 47 self-incompatible clones.

\section{Pod-set and pod production}

During April 1992, 75 self-compatible and 70 selfincompatible trees were identified in a small abandoned cacao estate of 155 trees at Mount St Benedict in Trinidad's Northern Range. The compatibility types of the trees were determined by selfing five 
bagged flowers per tree. Ten trees failed to flower so their compatibility type was not determined. The number of pods per tree was recorded on three occasions in 1992, first in May following pod-set, secondly in July at mid-development and finally at maturity in October.

\section{Electrophoresis}

Starch gel electrophoresis was carried out using the method of Lanaud (1987) as modified by Warren (1994). Thirty-seven self-compatible and 35 selfincompatible trees were selected at random from the Mount St Benedict estate. This population was selected for analysis because we had previously established that it was derived from a single cross segregating for selfcompatibility at a single locus (either the $A$ or $B$ locus) while the other two compatibility loci remained fixed for incompatibility (Kalai, unpublished). The ratio of 75 self-compatible trees to 70 self-incompatible trees in the plantation fits a $1: 1$ ratio $\left(\chi_{1}^{2}=0.172\right.$, $P=0.7-0.5$ ) expected for a $A a \times a a$ cross (where $a=$ self-compatible allele). Other Mendelian ratios, not presented here (Kalai, unpublished), also confirm that the plantation represents a segregating progeny. Since self-compatibility is recessive in cacao, all the incompatible trees in the population should be heterozygous for the trait.

For each tree young, flushing leaves were assayed electrophoretically for three enzymes: acid phosphatase $(A C P)$, isocitrate dehydrogenase $(I D H)$ and malate dehydrogenase $(M D H)$.

\section{Results and discussion}

\section{The 20-year trial}

The mean annual dry bean yields were plotted for both the 31 self-compatible and the 47 self-incompatible clones of the first trial (Fig. 1). Twenty years of field data demonstrate that the self-incompatible clones outyielded the self-compatible ones in all but a single year in the production of dry beans. The mean dry weight production of beans over the entire period was 21.44 $\mathrm{kg}$ for the self-incompatible clones and $17.03 \mathrm{~kg}$ for the self-compatible clones. The analysis of variance of these data shows that the self-incompatible clones produced a significantly greater dry bean yield than did the self-compatible clones $\left(F_{1,76}=10.71\right.$, $P=0.01-0.001$ ).

\section{Mount St Benedict material}

The mean numbers of pods per tree for both compatibility types (Fig. 2) show that although the self- incompatible trees produced slightly more mature pods than the self-compatible trees, the difference was nonsignificant because of a large tree-to-tree variance $\left(F_{1,143}=0.23, P>0.05\right)$. Interestingly, the self-compatible trees set three times more pods than did the incompatible trees $\left(F_{1,143}=78.11, P<0.001\right)$. These pods, which may represent a potential for increased yield, never reached maturity as they were aborted, a physiological phenomenon known to the cacao farmer as cherelle wilt (Fig. 2). The observed difference in flower-set between the compatibility types is similar to that reported between related selfing and outcrossing species (Solbrig \& Rollins, 1977). This is perhaps not

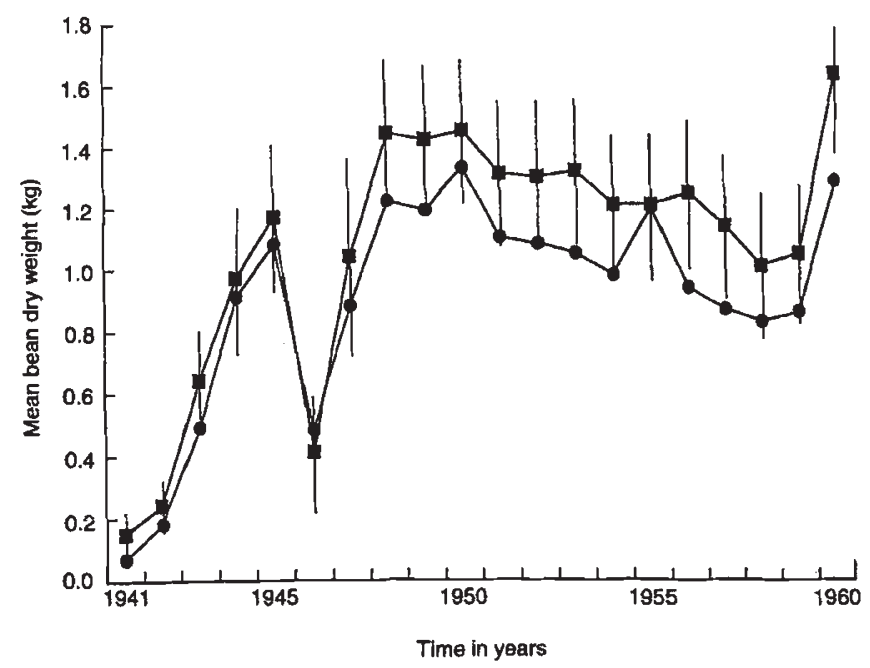

Fig. 1 Mean annual dry bean yields, based on 47 selfincompatible and 31 self-compatible clones of Theobroma cacao. Standard errors are shown on the self-incompatible data. $=$ Self-incompatible, $\bullet=$ self-compatible.

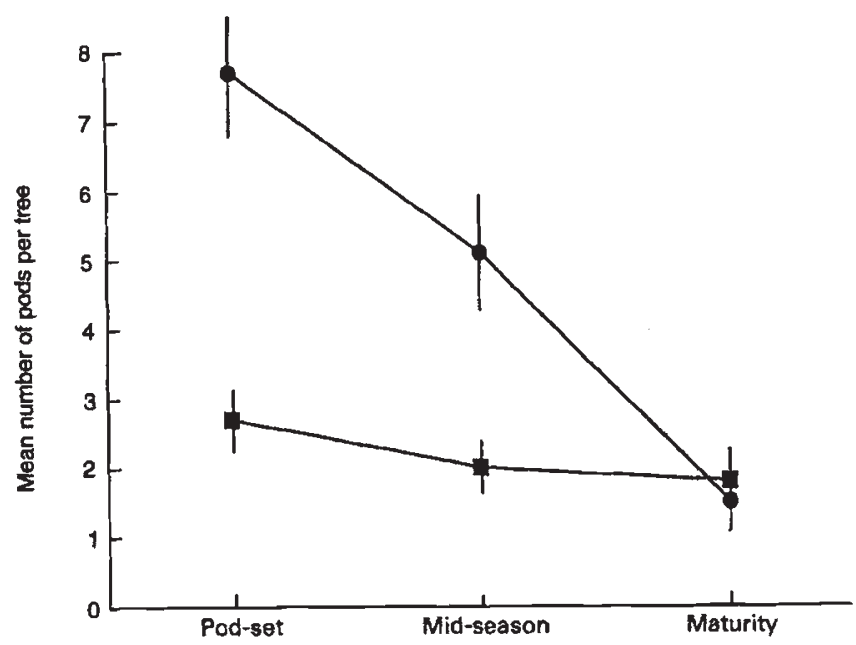

Fig. 2 Mean number of pods per Theobroma cacao tree (with standard errors) based on 70 self-incompatible and 75 self-compatible trees. $\boldsymbol{a}=$ Self-incompatible, $\bullet=$ selfcompatible. 
surprising since the self-compatible trees, although dependent upon insects for pollination, are not reliant upon their tree-to-tree movement.

Only a single locus was recorded for each of the three enzymes. Although $M D H$ is controlled by three loci (Lanaud, 1987) only the slowest migrating of these $(M d h-1)$ was recorded. The three enzymes are all dimeric and multiple alleles have been described for all loci (Warren, 1994). However, the Mount St Benedict population was found to contain only two alleles at each of the enzyme loci, designated slow and fast. For each of the three enzymes one of the homozygote classes was absent; the gels were thus scored by recording the genotype of all individuals as either heterozygous or homozygous. The results are shown for each compatibility type in Table 1 .

All three enzyme loci segregated in the expected 1:1 ratio of homozygotes to heterozygotes for a backcross. Analysis of the isozyme data revealed, however, significant nonrandom associations of loci with self-compatibility. A chi-square test on the segregation ratios confirmed the nonindependent assortment of selfcompatibility alleles and both the Acp alleles $\left(\chi_{1}^{2}=4.462, \quad P=0.05-0.02\right)$ and Idh alleles $\left(\chi_{1}^{2}=37.702, \quad P \ll 0.001\right)$. No significant association

Table 1 The cosegregation of isozyme alleles and compatibility types in Theobroma cacao

\begin{tabular}{lcc}
\hline Enzyme locus & $\begin{array}{c}\text { Heterozygote } \\
S F\end{array}$ & $\begin{array}{c}\text { Homozygote } \\
F F\end{array}$ \\
\hline Acp & & \\
$\quad$ Incompatible & 19 & 16 \\
Compatible & 11 & 26 \\
Idh & & 6 \\
Incompatible & 29 & 32 \\
Compatible & 5 & 17 \\
Mdh-1 & & 22 \\
Incompatible & 18 & \\
Compatible & 15 & Homozygote \\
Acp with Idh & & $F F$ \\
& & Acp \\
Idh & & 14 \\
Heterozygote $S F$ & Heterozgote & 28 \\
Homozygote $S S$ & 20 & \\
\hline
\end{tabular}

Numbers represent the number of individual trees scored with the specific genotype combination. $S S$, slow homozygote; $F F$, fast homozygote; $F S$, fast slow heterozygote. was found between the $M d h-1$ alleles and compatibility type $\left(\chi_{1}^{2}=0.859, P=0.5-0.3\right\rangle$. Not surprisingly, the $A c p$ and $I d h$ alleles were also found to segregate nonindependently $\left(\chi_{1}^{2}=7.802, P=0.01-0.001\right)$.

Since the individuals scored are full-sibs of a family equivalent to a backcross, the recombination frequency between these markers may be estimated by dividing the number of observed recombinants by the total $(72)$. This method estimates that the recombination frequencies $( \pm \mathrm{SE})$ are $32.5 \pm 5.7,15.3 \pm 4.2$ and $33.3 \pm 5.6$ between the compatibility locus and $A c p$, the compatibility locus and $I d h$ and between the two enzyme loci, respectively. This suggests that the order of the loci is $A$ or $B-I d h-A c p$. Thus, in the Mount St Benedict estate isozyme genotype can be used as a predictor of self-compatibility, higher pod set and possibly longterm decreased yield. However, in other crosses selfcompatibility may be controlled by the other two compatibility loci (or by any combination of the three loci) and additional genetic markers will be required.

\section{Acknowledgements}

We would like to thank Fr Francis and the Monks of Mount St Benedict for access to the field site. The financial support of the BCCCA is gratefully acknowledged. We would also like to thank Mervyn Humphreys for commenting on the manuscript.

\section{References}

COPE, F. W. 1962. The mechanism of pollen incompatibility in Theobroma cacao L. Heredity, 17, 157-182.

KNIGHT, R. AND RODGERS, H. H. 1955. Incompatibility in Theobroma cacao. Heredity, 9, 69-77.

LANAUD, c. 1987. Nouvelles données sur la biologie du cacaoyer (Theobroma cacao L.). $\mathrm{PhD}$ thesis, Université de Paris Sud.

Pound, F. J. 1935. The progress of selection, 1934. Report on cacao research, 1934, pp. 7-11. Imperial College of Tropical Agriculture, Trinidad.

SOLBRIG, O. T. AND ROLLINS, R. C. 1977. The evolution of autogamy in species of the mustard genus Leavenworthia. Evolution, 31, 265-281.

WARREN, J. M. 1992. Cocoa breeding in the twenty-first century. Proc. International Cocoa Genetic Resources Workshop, Trinidad. In press.

WARREN, J. M. 1994. Isozyme variation in a number of populations of Theobroma cacao obtained through various sampling regimes. Euphytica, 72, 121-126.

WARREN, J. M. AND KENNEDY, A. J. 1991. Cocoa breeding revisited. Cocoa Growers' Bulletin, 44, 18-24.

WILDE, J., WAUGH, R. AND POWELL, w. 1992. Genetic fingerprinting of Theobroma clones using randomly amplified polymorphic DNA markers. Theor. Appl. Genet., 83, 871-877. 